\title{
From Management Information Systems to Business Intelligence: The Development of Management Information Needs
}

\author{
Rimvydas Skyrius, Gèlytė Kazakevičienè, and Vytautas Bujauskas \\ Economic Informatics Department, Vilnius University, Lithuania
}

\begin{abstract}
Despite the advances in IT, information systems intended for management informing did not uniformly fulfil the increased expectations of users; this can be said mostly about complex information needs. Although some of the technologies for supporting complicated insights, like management decision support systems and technologies, experienced reduction in interest both from researchers and practitioners, this did not reduce the importance of well-supported business informing and decision making. Being attributed to the group of intelligent systems and technologies, decision support (DS) technologies have been largely supplemented by business intelligence (BI) technologies. Both types of technologies are supported by respective information technologies, which often appear to be quite closely related. The objective of this paper is to define relations between simple and complex informing intended to satisfy different sets of needs and provided by different sets of support tools. The paper attempts to put together decision support and business intelligence technologies, based on common goals of sense-making and use of advanced analytical tools. A model of two interconnected cycles has been developed to relate the activities of decision support and business intelligence. Empirical data from earlier research is used to direct possible further insights into this area.
\end{abstract}

Keywords - management decision support, business intelligence, information needs

\section{INTRODUCTION}

$\mathrm{T}$ $\mathrm{HE}$ job of informing business managers and other people in charge of running organizations stays on the agenda of many researchers and practitioners around the information systems and information management community. While the advances in technological foundations of management information systems have been impressive, the advances in efficient satisfaction of management information needs have been less impressive. The development of systems for managerial information needs, while having a rich history of several decades, has been based on a heterogeneous set of needs: some of these needs stay stable (developing, implementing and adjusting strategy; keeping track of own activities), and some evolve or have a turbulent life cycle: monitoring close environment; looking out for threats and opportunities. Information environment (support infrastructure) is driven by the nature of business activities. On one hand, this nature is recurrent and cyclical, supported mostly by the function of a MIS. On the other hand, this nature is turbulent and unpredictable, requiring intelligent and insightful support; this is a function of a BI system and related applications - decision support, competitive intelligence, operational intelligence, early warning systems and other types of systems to support monitoring, sense-making and problem solving.

The recent research on complex information needs including decision support and business intelligence has been diversified into quite a few related areas; far from being an exhaustive set, several examples follow. Lemieux and Dang [7] have researched the issues of accountability for decision making, and suggested tools for tracking the decision-making reasoning of human agents, thus adding to the research on a problem of experience management. Thorleuchter and Van den Poel [17] have investigated the use of website content analysis in partner search for improved research and technology collaboration planning, adding to the body of research on information integration. Saad et al [11] have researched a conceptual framework for early warning information systems for crisis situations, expanding the research on intelligence technologies for monitoring and detection. Castano [1] has researched the possibility of putting together business process management (BPM) and data mining techniques to provide intelligent BPM management functions. Redondo-Garcia et al [10] have researched information integration tasks when using disparate (heterogeneous) information sources.

The sample of research directions presented above for a long time has been attributed to the area of decision support systems and technologies, serving the complex or high-end side of user information needs. In the field of technologies for satisfying complex information needs, the once-prominent area of management decision support systems (DSS) apparently has settled to stable levels of both academic and practitioner activities [9]. However, a somewhat faded interest in decision support systems does not imply any reduction in importance of well-supported decision making, as well as general awareness of the state of internal and external business environment. On 
the contrary, the current economic situation in most settings demands an efficient and reliable, „military grade“ management environment to support decisions, insights, recovery or mere survival.

Decision support alone, being reactive and activated only when a problem is encountered, eventually proved to be insufficient. The problem solving context received IT-based support mostly from the resources of a regular information system, therefore of a limited nature and in most cases complicated by time pressures. An alternative use of decision support, if coupled to a proactive monitoring of the environment, ensured better understanding of the problem context, leading to higher decision quality. A term "business intelligence" came into use, serving as an umbrella term for tools and technologies that let business information users stay aware of changes in internal and external environments.

The research problem of this paper is centered around how the current array of technologies and approaches provides support for functions of insight building. Currently there is a confusion in defining whether management information systems overlap with intelligence systems, and whether business intelligence is a part of decision support function, or vice versa; eventually this confusion spreads to business management community which at all times has expressed the need for insight building and reliable decision support which would justify substantial investments into support technologies. In this paper, the authors have decided to use the results of their earlier research to make an attempt in developing a model positioning business intelligence and decision support functions.

The paper is structured as follows. Section 1 defines the dimensions of the problem and the goal of the paper. Section 2 clarifies the definition of business intelligence and its information needs. Section 3 defines a relation between the areas of decision support and business intelligence. Section 4 presents empiric data on user responses towards decision support anad business inteligence functions. Finally, Section 5 presents conclusions and directions for further research.

\section{II.BUSINESS INTELLIGENCE AND INFORMATION NEEDS}

Although business intelligence is regarded as a relatively new term, with authorship assigned to Howard Dressner of Gartner Group in 1989, we can have a retrospective look at the mission of management information systems (MIS), whose role of keeping management aware of the state of business has never been downplayed, and mission definitions for MIS sound very much like the mission definitions for business intelligence today. A few explanations of MIS role from earlier sources are presented below:

- "Two types of information for strategy implementation are in use. The first one is the external information, used for strategy development. The second type is internal information, used to monitor strategy execution" [14].

- "A management information system refers to many ways in which computers help managers to make better decisions and increase efficiency of an organization's operation" [7].

- "For information to be useful for managerial decision making, the right information (not too much and not too little) must be available at the right time, and it must be presented in the right format to facilitate the decision at hand" [4].

- "A management information system is a business system that provides past, present, and projected information about a company and its environment. MIS may also use other sources of data, particularly data about the environment outside of the company itself." [6].

- "The systems and procedures found in today's organizations are usually based upon a complex collection of facts, opinions and ideas concerning the organization's objectives. ... For an organization to survive, it must learn to deal with a changing environment effectively and efficiently. To accomplish the making of decisions in an uncertain environment, the firm's framework of systems and procedures must be remodeled, refined, or tailored on an ongoing basis." [3].

There are definitions of business intelligence that do not differ much from the above definitions; e.g., Vuori [20] states that " ... business intelligence is considered to be a process by which an organization systematically gathers, manages, and analyzes information essential for its functions". In order to have a more precise definition of business intelligence, we have to decide whether all informing functions are ,intelligence" because they increase awareness, or does BI have a clear separation from other (lower level) informing functions. If so, the separation criteria between BI systems and any other management information systems have to be defined. For the purposes of this paper, we will use the division of management information needs along two dimensions - their simplicity or complexity, and common or specific focus, as presented in the Table 1 and based on earlier work by one of the authors [14]:

TABLE 1.

RELATION OF SIMPLE-COMPLEX AND COMMON-SPECIAL INFORMATION NEEDS

\begin{tabular}{|l|l|l|}
\hline & Simple needs & Complex needs \\
\hline $\begin{array}{l}\text { Special needs } \\
\text { (problem- } \\
\text { specific) }\end{array}$ & $\begin{array}{l}\text { Simple special } \\
\text { needs }\end{array}$ & $\begin{array}{l}\text { Complex special } \\
\text { needs }\end{array}$ \\
\hline $\begin{array}{l}\text { Common needs } \\
\text { (available } \\
\text { permanently) }\end{array}$ & $\begin{array}{l}\text { Simple common } \\
\text { needs }\end{array}$ & $\begin{array}{l}\text { Complex common } \\
\text { needs }\end{array}$ \\
\hline
\end{tabular}

The mission of BI becomes clearer if weighted against the types of served information needs. Regarding the positioning of these needs against the axis of simple-complex information needs, they usually fall into the more sophisticated part of the information needs complexity spectrum. Same can be said 
about the process of decision making, which often requires sophisticated tools to support awareness, communication, sense-making and evaluation of risks. The dimension of common and special information needs separates decision making from the rest of business intelligence in a sense that while decision support activities are directed towards a certain problem which has been recognized and has created a task of its solving, business intelligence can be considered an activity which, apart from encompassing decision support, has a permanent nature and allows the discovery of problems and general awareness about the state of activities.

\section{DECISION SUPPORT AND BUSINESS INTELLGENCE}

\section{PROCESSES}

\section{A. Structure of Decision SupportProcess}

A decision support process includes a number of stages, and if accumulation and subsequent use of experience is included, the process takes a cyclical nature (Fig. 1, from [13]):

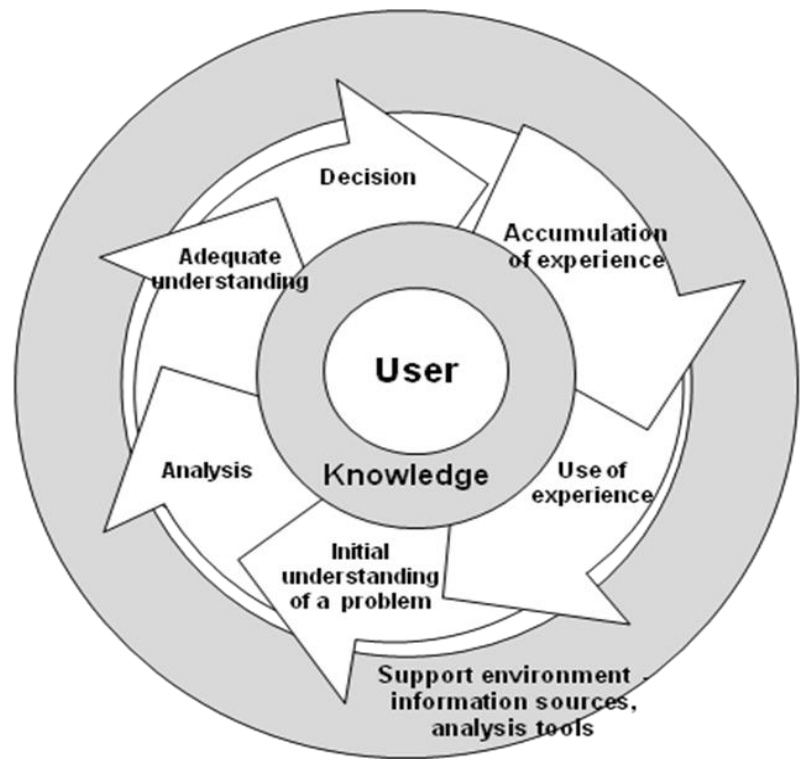

Fig. 1. The decision support process

The structure of the decision support process can be related to relevant information needs:

1. Monitoring (using previous experience): the environment, both internal and external, is being watched to notice things worth attention; simple and common information needs prevail.

2. In the case of recognizing a situation of interest (initial understanding of a problem or opportunity) the situation is evaluated and given extra attention to achieve desired understanding. At this stage special information needs arise.

3. Additional analysis and decision development is required if the situation is complex enough (semistructured or unstructured); simple needs are complemented by complex needs; more information is brought into decision making environment; specific problem-solving tools such as formal approaches and models are likely to be used to achieve an adequate understanding of a problem.

4. The decision-making stage involves formerly available as well as newly gained understanding of the situation, and the decision maker or makers will use all possessed knowledge to arrive at the best possible decision, time or other circumstances permitting. In this paper, the term "knowledge" is deliberately avoided most of the time, but here it serves to show that data or information alone are insufficient for decision making; all that is known will be used in its entirety, and new knowledge most likely will be gained.

5. The experience accumulation stage records the newly gained experience from both decision making and its implementation, and keeps it for possible reuse. Special needs become common, adding new material to the already available body of experience, and the need to capture the essential features of the recorded case keeps this sort of information need in the complex segment. This phase should also include the practical experience in decision implementation, which can sometimes reveal additional circumstances of the problem.

6. The use of new experience, along with that formerly accumulated, brings the process back to stage 1 monitoring.

Stage 1 of the above process is directly related to (or can be considered a part of) business intelligence, because that's where the actual monitoring of the business environment is being done. Stage 2 is a principal point of joining business intelligence and decision support.

As we can see, during the decision making process the focus of information needs moves around the quadrants of Table 1: stage 1 concentrates in the simple/common sector; stage 2 moves on to simple/special sector, stages 3 and 4 concentrate in the special/complex sector, stage 5 moves into complex common sector, and finally stage 6 brings the focus back to simple/common sector.

\section{B. Structure of Business Intelligence Process}

The business intelligence process, too, takes a cyclical nature (Fig. 2., from [20]), and includes the stages of information needs definition, information collection, information processing, analysis, information dissemination, information utilization and feedback. The cycle structure is justified if the received feedback helps to reevaluate or redefine information needs.

In business intelligence process, there's usually no clear concentration on a specific topic or problem, and the resources of a BI system are used for constant monitoring of internal and external business environment. In other words, such systems serve common information needs to keep users informed about the state of business environment, often combining a monitoring function with alerts, exception reports and other tools to draw attention to changes or inconsistencies. Therefore, an important feature of BI systems is their ability to 
produce a complete composite view that would help avoiding surprises.
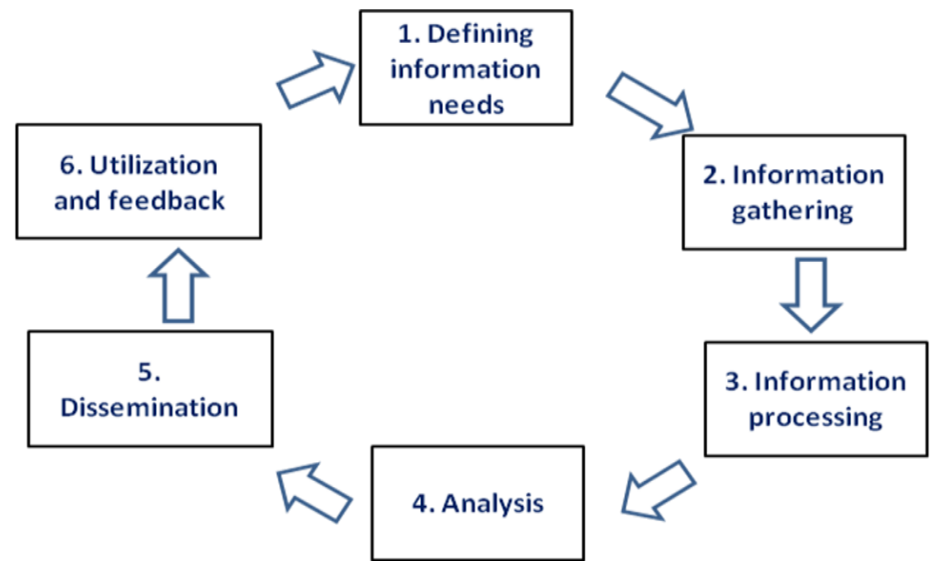

Fig. 2. A generic business intelligence process model [20]

The business intelligence cycle, as presented in Fig. 4., raises several questions. First of all, it does not disclose the difference between regular management information systems or their current incarnation, ERP systems, and business intelligence systems. It is unclear, for example, whether external information is used in the cycle, and if so, in what ways. Secondly, the cyclical feedback should invoke the reevaluation of information needs, as business conditions change, or some needs have been incorrectly assessed from previous cycles (inclusion of irrelevant information or omission of important information).

From the above descriptions of technologies and processes for both decision support and business intelligence we can define two different but interrelated cycles: cycle 1 for business intelligence process, and cycle 2 for decision support process (Fig. 3).

As cycles 1 and 2 unfold, the focus moves around different types of information needs. In cycle 1, the steps of information gathering and processing can be attributed to the common and simple part of information needs. The analysis step uses processed information and produces derivative results that produce additional insight and move from simple to more complex needs. If a problem situation is recognized, special needs arise, and cycle 2 is activated. For a problem analysis, special needs may be both of simple and complex nature, depending upon the severity of a problem. A problem-specific model is developed for better understanding of the problem and evaluating the alternatives. Decision implementation brings in valuable experience that is saved for later reuse and, together with other experience, satisfies common information needs important both for future business intelligence and decision making.

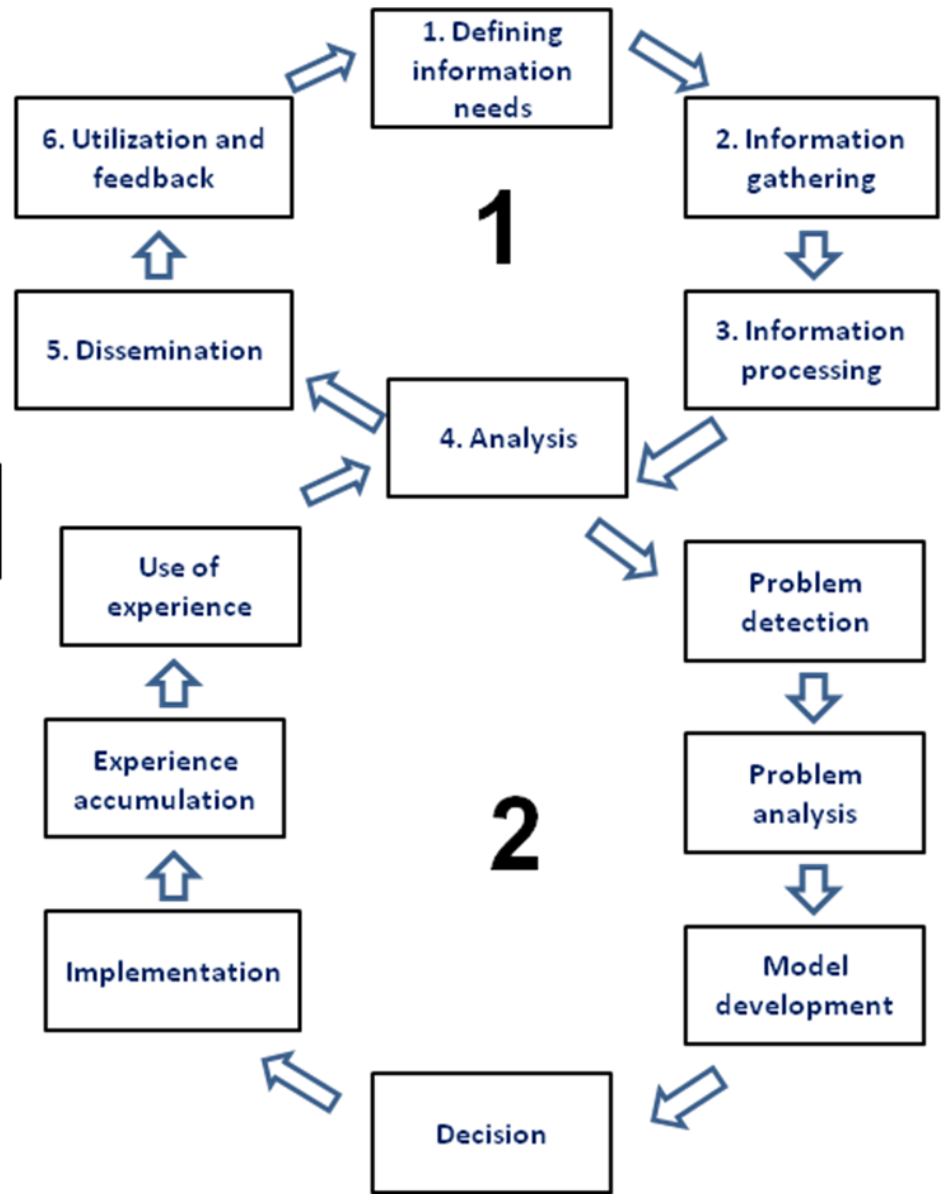

Fig. 3. Relation of business intelligence (1) and decision support (2) cycles

\section{USER RESPONSES ON IT USE FOR DECISION SUPPORT AND BUSINESS INTELLIGENCE}

The opinions on IT role in supporting the sophisticated side of information needs can be roughly split into deterministic approaches and behavioural, human-centered approaches. The former assign prime importance to IT performance and ability to automate complex analytical procedures [2], while the latter assign prime importance to human skills and creative powers ([16], [5], [19]), at the same time stating that the majority of existing decision support and analytical tools are technologycentric rather than user-centric. The conflicting attitudes have initiated a survey, performed earlier by one of the authors [14], where issues like monitoring of internal and external environment, IT role in the monitoring process, and experience management have been researched to gain insight on IT use to support the compl;ex side of management information needs, including DS and BI. The survey had yielded 250 responses from a convenience sample of managers of small and medium businesses in a Central-Eastern Europe country.

Regarding the monitoring of internal organization environment, the users appeared to be quite comfortable using IT for monitoring key data about their organization's activities. Such information is contained within their in-house information system that has been created to monitor these activities. The absolute majority of responders (161 or $64.4 \%$ ) have indicated that IT is used to monitor all issues relating to an organization's internal information needs; such needs are 
attributed mostly to the simple common needs. The information system-based information tasks are largely routine, and satisfaction of this type of information needs does not pose any significant problems.

For external monitoring the use of IT is significantly lower; the number of responders having indicated that they use IT to monitor all external issues has been 125 , or $50 \%$; 122 responders, or $48.8 \%$, had stated that they use IT for some of the external monitoring issues. The lower numbers of use do not point to second-rate importance of external monitoring; rather, they indicate that the sources of external information are not under the control of a single own information system, as it is in the case of internal information sources. The external environment, being an important source of changes, opportunities and risks, is much more turbulent, and there is a greater variety of issues to be monitored, information sources, formats, and access modes; this variety significantly complicates the use of IT for external monitoring.

Supporting the detection of important changes, IT had been considered a helpful aid in monitoring and detecting changes, but rather limited in supporting information needs for sensemaking. The absolute majority of responses (105 out of 207 responders having indicated that IT has some role in detecting important changes, or about $51 \%$ ) stressed the role of IT as a principal technical support tool. No responses stated that IT had significantly supported the function of sense-making (revealing important changes in the environment).

The reuse of experience and competence information is one of the most important functions in the process chains of BI and DS; this statement can be supported by a seemingly growing number of published work on experience management systems. The results of the survey have indicated that the reuse of important problem-solving and decision making experience is of mixed success; recorded practice is reused - in most cases conditionally, as situations change and information needs have to be constantly re-evaluated. The survey had also shown that experience records are recorded in all convenient ways: free text format in digital media, structured format (with some standardized features and values) in digital media, and same on paper. IT role can be seen mostly in arranging, managing structures, imposing standards, and allowing easy filtering and retrieval. Level of reuse is limited due to changing context, although the reuse of templates, structures, models and other procedural issues is commonplace.

Decision-making information needs are hard to plan because of their variety and unstructuredness. Regarding this issue, the respondees have been asked about:

- decision making infomation needs that are known beforehand, and the principal types of such information;

- decision making information needs that are not known beforehand and emerge in the process of developing a decision, and the principal types of such information.

The known information needs relate to information whose content and location are known and accessible because of earlier experience, or this information is already available. This information or tools for its access can be placed in close proximity to the decision makers. The distribution of responses between the different types of this information is given in Table 2.

TABLE 2

KNOWN INFORMATION NEEDS FOR DECISION MAKING

\begin{tabular}{|c|c|c|}
\hline Type of information & $\begin{array}{r}\text { No. of } \\
\text { cases }\end{array}$ & Percent \\
\hline $\begin{array}{l}\text { Market information (customers, sales, } \\
\text { needs, opportunities) }\end{array}$ & 49 & $19,6 \%$ \\
\hline $\begin{array}{l}\text { Competition information (competitors' } \\
\text { status, strength, intentions, actions) }\end{array}$ & 29 & $11,6 \%$ \\
\hline $\begin{array}{l}\text { Internal information (financials, } \\
\text { capacity, inventory) }\end{array}$ & 27 & $10,8 \%$ \\
\hline $\begin{array}{l}\text { Legal information (laws, regulations, } \\
\text { standards) }\end{array}$ & 26 & $10,4 \%$ \\
\hline No such cases & 26 & $10,4 \%$ \\
\hline Technical information & 2 & $0,8 \%$ \\
\hline Did not specify & 91 & $36,4 \%$ \\
\hline Total: & 250 & $100,0 \%$ \\
\hline
\end{tabular}

A separate important group of information needs is the unexpected information needs, which emerge mostly because of turbulent business nature, are hard to plan, and the use of programmed solutions is rather limited. The distribution of responses between the different types of this information is given in Table 3 .

TABLE 3

UNEXPECTED INFORMATION NEEDS FOR DECISION MAKING

\begin{tabular}{|l|r|r|}
\hline Type of information & \multicolumn{1}{l|}{$\begin{array}{l}\text { No. } \\
\text { of } \\
\text { cases }\end{array}$} & Percent \\
\hline No such cases & 86 & $34,4 \%$ \\
\hline $\begin{array}{l}\text { Yes, there have (without specifying the } \\
\text { information) }\end{array}$ & 46 & $18,4 \%$ \\
\hline Market information & 23 & $9,2 \%$ \\
\hline Internal information & 15 & $6,0 \%$ \\
\hline Competition information & 14 & $5,6 \%$ \\
\hline Legal information (e.g., & 14 & $5,6 \%$ \\
\hline Technical information & 14 & $5,6 \%$ \\
\hline $\begin{array}{l}\text { Informal, "soft" information } \\
\text { opinions, foresights) }\end{array}$ & $5,8 \%$ \\
\hline $\begin{array}{l}\text { Confidential information (e.g., customer } \\
\text { reliability checks) }\end{array}$ & 21 & $8,4 \%$ \\
\hline Did not specify & $\mathbf{2 5 0}$ & $100,0 \%$ \\
\hline
\end{tabular}

The distribution of both responses is not much different, and suggests that often decision makers have to look deeper into existing issues ("more of the same"). However, the significant presence of unexpected information needs might require a set of support tools that would allow tailored approaches using assorted decision support techniques - e.g., modeling, data mining, text mining, information integration and others.

The above separation of information needs into known and unexpected roughly corresponds to the related cycles pictured in Fig.5, where the business intelligence cycle is performed mostly against known information needs. If a specific problem 
is detected, the known needs together with readily available information move to the decision support cycle, where additional information needs of unexpected nature are likely to emerge. This approach can be useful in designing business intelligence environments incorporating a sub-level for decision support, with generic functionality contained mostly in the $1^{\text {st }}$ cycle, and the problem-specific tools and techniques in the $2^{\text {nd }}$ cycle.

\section{V.DISCUSSION AND CONCLUSIONS}

There's no doubt that the need for well-informed business decisions, as well as for general awareness of developments in the business environment, will remain acute. The current state of management decision support gets more complicated as rapidly changing conditions often require swift reaction, information overload is commonplace, and additional issues arise regarding information quality [9]. Under these conditions, a need for right information at the right time and in the right place remains essential, and the well-aimed and reasonable use of support technology can increase decision making quality and efficiency, regardless of whatever name this technology is bearing at the moment.

We suggest here to use here the arguments presented in this paper, regarding the development of an efficient information environment for decision makers. It has been proposed that such environment should be split into two tiers:

- the first tier containing a simple set of support tools that are close and easy to use;

- the second tier containing more distant and more complicated information sources and processing techniques that are required much less often;

- manageable support environment that allows easy switching of items between tiers, similar to the form of managerial dashboards with interchangeable items on display.

The items contained in the first ("lite") tier would be required most of the time, simple to use and able to be configured to the users' needs:

- basic data on internal and external environment: sales, market share, cash-at-hand, order or project portfolio, comparative figures by time/place/product etc.;

- information access tools: simple search in own sources databases and data warehouses, simple search in public sources, tools for arranging search results (e.g., by relevance or size), easy classification and annotation;

- tools for simple calculations: templates, financial models, other simple models.

The second ("heavy") tier might include:

- access to more distant and complex information sources with advanced search tools;

- modelling tools for forecasting, simulation, scenario development;

- data analysis and presentation technologies - drill-down tools, OLAP queries, data and text mining facilities, graphing and visualization tools.
Such split of functionality would roughly reflect required functions for generic business intelligence and decision support cycles respectively. It would also allow for required cross-functionality in the cases when simple decision support needs would be well-served by first tier functions alone, or when business intelligence needs would required more advanced tools. The more defined set of features for both tiers of the support environment could lead to a possible set of requirements for the interface design of an information environment for decision makers.

The further research is planned in several related and more specific directions. Firstly, it is important to research what part of business decisions are adequately supported by the first tier of the support environment, thus possibly defining an efficient and economical set of support tools. Secondly, the issues of handling experience information and providing experience support should be investigated in more specific terms of what key information on decisions already made should be recorded to create brief yet essential context, and what is the reusability and relevance rate for different types of experience records.

\section{REFERENCES}

[1] Castano A. P. Prototype of assignment intelligent adaptive of service providers inside of ESB with data mining. International Journal of Artificial Intelligence and Interactive Multimedia, 1(2), 39-43 (2012).

[2] Davenport T. Competing on analytics. Harvard Business Review, January 2006, 99-107 (2006).

[3] FitzGerald J., FitzGerald A., Stallings W. Fundamentals of systems analysis. New York, NY: John Wiley \& Sons (1981).

[4] Gremillion L., Pyburn P. Computers and information systems in business. New York, NY: McGraw-Hill (1988).

[5] Johnstone D., Bonner M., Tate M. Bringing human information behaviour into information systems research: an application of systems modelling. Information Research, 9(4), paper 191 (2004). http://InformationR.net/ir/9-4/paper191.html.

[6] Kroenke D., McElroy M., Shuman J., Williams M. Business computer systems. Santa Cruz, CA: Mitchell Publishing (1986).

[7] Lemieux V., Dang T. Building Accountability for Decision Making into Cognitive Systems. WorldCIST 2013, March 27-30, Algarve, Portugal (2013).

[8] Pick J. Computer systems in business. Boston, MA: PWS Publishers (1986).

[9] Power D. Decision Support Basics. Business Expert Press (2009).

[10] Redondo-Garcia J.L., Botón-Fernandez V., Lozano-Tello A. Linked Data Methodologies for Managing Information about Television Content. International Journal of Artificial Intelligence and Interactive Multimedia, 1(6), 36-43 (2012).

[11] Saad M., Mazen Sh., Ezzat E., Zaher H. Towards a Conceptual Framework for Early Warning Information Systems (EWIS) for Crisis Preparedness. WorldCIST 2013, March 27-30, Algarve, Portugal (2013).

[12] Shim J.P., Warkentin M., Courtney J., Power D., Sharda R., Carlsson C. Past, present, and future of decision support technology. Decision Support Systems, 33, 111-126 (2002).

[13] Skyrius R. Satisfying Complex End of User Information Needs: User Experiences. The Business Review, Cambridge, 6(2), December 2006, 132-138 (2006).

[14] Skyrius R. The current state of decision support in Lithuanian business. Information Research, 13(2), paper 345 (2008). http://InformationR.net/ir/31-2/paper345.html.

[15] Skyrius R., Bujauskas V. Business intelligence and competitive intelligence: separate activities or parts of integrated process? The Global Business, Economics and Finance Research Conference. London (2011).

[16] Sjoberg L. The distortion of beliefs in the face of uncertainty. SSE/EFI Working Paper Series in Business Administration, 2002:9. (2002). 
International Journal of Artificial Intelligence and Interactive Multimedia, Vol. $2, N^{o} 3$.

[17] Thorleuchter D., Van den Poel D. Analyzing Website Content for Improved R\&T Collaboration Planning. WorldCIST 2013, March 2730, Algarve, Portugal (2013).

[18] Tom P. Managing information as a corporate resource. Glenview, IL: Scott, Foresman and Company (1987).

[19] Turpin M., \& du Plooy N. Decision-making biases and information systems. In The 2004 IFIP International Conference on Decision Support Systems (DSS2004), pp. 782-792, Prato, Italy (2004).

[20] Vuori V. Methods of Defining Business Information Needs. Frontiers of e-Business research conference. Tampere University of Technology, Tampere, Finland (2006).

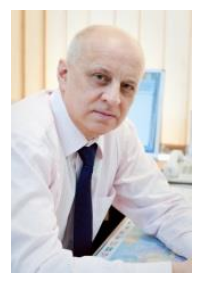

Rimvydas Skyrius is a professor at the Economic Informatics department, Faculty of Economics, Vilnius University, Lithuania. He has a $\mathrm{PhD}$ in Management (Management Information Systems) from ASU-Moskva research institute, Moscow, former Soviet Union, 1986. From 2008 he is a head of the Economic informatics department. His research interests include Management Information Needs, Management Decision Support, Business Intelligence, Information Systems Usability.

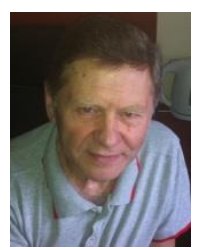

Vytautas Bujauskas is an Associate Professor (retired) at the Economic Informatics department, Faculty of Economics, Vilnius University, Lithuania. He has a PhD in Management (Management Information Systems) from Moscow Plekhanov institute of National Economy, 1978. His research interests include Management Information Needs, Management Decision Support, Business Intelligence.

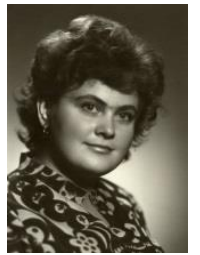

Gelyte Kazakeviciene is an Associate professor at the Economic Informatics department, Faculty of Economics, Vilnius University, Lithuania. She has a $\mathrm{PhD}$ in Mathematics from Vilnius University, 1993. Her research interests include Management Information Needs, Management Decision Support, Financial applications. 